\title{
The C-Terminal Segment Is Essential for Maintaining the Quaternary Structure and Enzyme Activity of the Nitric Oxide Forming Nitrite Reductase from Achromobacter cycloclastes
}

\author{
Wei-Chao Chang,* J ang-Yi Chen,* Tschining Chang, † Ming-Yih Liu,‡ William J . Payne, \\ J ean LeGall,‡ and Wen-Chang Chang*, \\ *Institute of Biochemical Science, National Taiwan University, Taipei, Taiwan; † nstitute of Biological Chemistry, \\ Academia Sinica, Taipei, Taiwan; and ‡Department of Biochemistry and Molecular Biology and \\ $\S$ Department of Microbiology, University of Georgia, Athens, Georgia
}

Received J uly 24, 1998

\begin{abstract}
We have constructed and expressed a series of mutated nitrite reductase (NIR) mutants based on the sequence of NIR from Achromobacter cycloclastes. Deleting a pentapeptide, an undecapeptide, or a heptadecapeptide from the C-terminus of NIR resulted in a series of C-terminal deletion mutated proteins designated as NIR-5, NIR-11, and NIR-17, respectively. A C-terminally extended mutated protein, NIR +8 , was also produced, which contains an extra octapeptide attached to the C-terminus of the wild-type NIR. An SDS-PAGE system using tris-tricine buffer could retain the native NIR in its trimeric form, thus offering a convenient method to check the quaternary structure of NIR analogs. By using this system it was found that NIR-5 was maintained as trimer and retained $\mathbf{7 2} \%$ of wild-type enzyme activity. However, both NI R-11 and NI R-17 behaved as monomers in the SDS-PAGE and lost all their enzyme activity. Although NIR +8 maintained its trimeric structure it was enzymatically inactive. These results clearly indicate that the C-terminal undecapeptide is essential for maintaining the quaternary structure as well as the full enzymatic activity, as expected from the X-ray crystallography studies. $\odot 1998$ Academic Press
\end{abstract}

There are two types of nitric oxide forming nitrite reductase: $\mathrm{cd}_{1}$ cytochrome nitrite reductase $\left(\mathrm{cd}_{1} \mathrm{NIR}\right)$ and copper nitrite reductase (CuNIR) (1). Both are involved in the reduction of nitrite in the denitrifying, respiratory pathway. It is known that $\mathrm{cd}_{1} \mathrm{NIR}$ transfers electrons from cytochrome $C_{551}$ to nitrite ions to perform its function, and that the active enzyme is a dimer. The CuNIR accepts electrons from azurin (Pseudomonas aureofaciens) (2), pseudoazurin (Alcaligenes faecalis s-6) (3) or a blue copper protein (Achro- mobacter cycloclastes) (4) and then transfers them to the nitrite ions. A detailed account of the electron transport steps were further demonstrated by using site-directed mutagenesis of A. faecal is NIR(5). It was shown that electons transfer from reduced pseudoazurin to the type I copper and then to the type II copper and finally to the nitrite. But the structure of active enzyme remains disputed $(6,7)$. X-ray crystallography showed that CuNIR is organized as a trimer $(8,9)$, and that hydrogen bonds form an extensive network both within and between subunits to maintain its quaternary structure. Moreover, the interaction of residues 13 and 14 of one subunit with residues 336-340 of another is one of the key packing forces maintaining the trimeric structure(9). We report herein, by using site-directed mutagenesis, that the C-terminal segment of about 10 residues of a CUNIR is important for maintaining both the trimeric structure and the enzymatic activity.

\section{MATERIALS AND METHODS}

Bacterial strains and plasmids. E.coli J M109 used for plasmid cloning was purchased from Promega Inc. E.coli, strain M15 (PREP4), derived from strain K12, was purchased from Qiagen Inc. and used for gene expression. The plasmids, pGemT, pGem3zf(+) (Promega) and pUC19, were used as cloning vector.

Media. E.coli, strains were cultured in L-broth aerobically at $37^{\circ} \mathrm{C}$. The concentration of ampicillin was $50 \mu \mathrm{g} / \mathrm{ml}$ for blue/white colony selection. IPTG, $0.5 \mathrm{nM}$, and X-Gal, $40 \mu \mathrm{g} / \mathrm{ml}$ (final concentration), were added to the medium. For the expression of NIR analog proteins under control of E.coli T5 promotor, two lac operator sequences and 2 mM IPTG were added.

Chemicals and enzymes. All restriction endonucleases and other DNA modification enzymes were purchased from Boehringer Mannheim or Promega Inc. [a- $\left.{ }^{32} \mathrm{P}\right] \mathrm{dATP}$ and $\left[\mathrm{a}^{35} \mathrm{~S}\right] \mathrm{dATP}$ were purchased from Amersham Inc. and the recombinant gene expression and the protein purification kits from Qiagen Inc. The gradient gel, tris- 

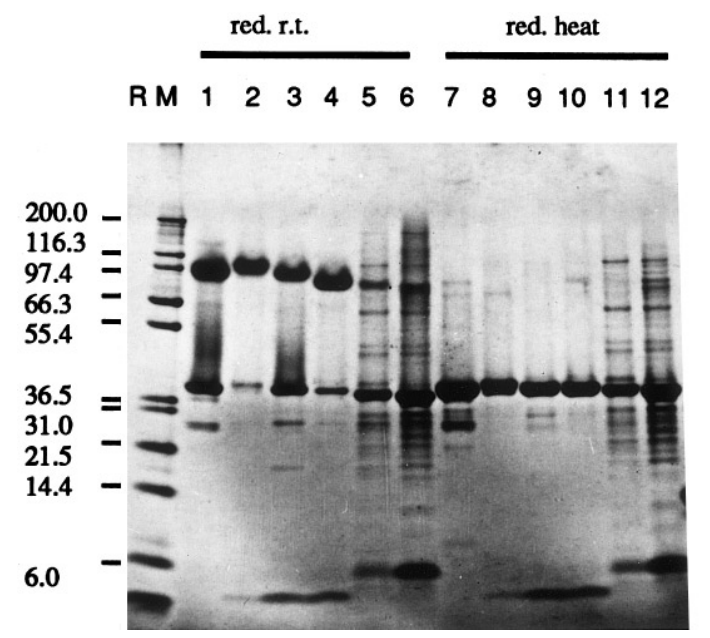

FIG. 1. The effect of heating on the protein profile in the tristricine SDS-PAGE system. Lanes 1-6: samples treated with reducing agent together with SDS and kept at room temperature for $5 \mathrm{~min}$ migrated as trimer form. Lanes 7-12: samples reduced and heated at $95^{\circ} \mathrm{C}$ for $5 \mathrm{~min}$ migrated as monomer. Lanes 1 and 7: NIR purified from A. C. Lanes 2 and 8: NIR+8. Lanes 3 and 9: E. coli expressed NIR. Lanes 4 and 10: NIR-5. Lanes 5 and 11: NIR-11. Lanes 6 and 12: NIR-17. RM: protein molecular weight maker.

glycine, tris-tricine buffer and sample buffer for SDS-PAGE were purchased from Novel Experimental Technology.

Cloning of NIR and its mutated genes. The cloning of the NIR gene (pQNIR) was described previously (10). For cloning of the C-terminally extended or deleted NIRs, the following primers were used: 5'GATGACGATGACCAAAGCAGCCGGTGC3' (N-terminal primer, for every mutated genes) 5'CATCGACGCCGGCTTGACGAC3' (C-terminal extended primer). 5'CTAGGTCACCTTGAAGTGGCCGGC3' (for NIR-5), 5'CTAATCATCGTTCCATTCGCCGGT3' (for NIR-11) and 5'CTAGACGACCGATGTCATCAGATC3' (for NIR-17). Polymerase chain reaction (PCR) was performed using the above primers and $\mathrm{pQNIR}$ recombinant plasmid as template to produce those modified coding sequences.

\section{RESULTS AND DISCUSSION}

The recombinant NIRs expressed in E.coli were easily purified and refolded to the native states as judged by absorption spectrum, SDS PAGE and activity assay as described earlier(10). NIR-11 and NIR-17 were expressed at low levels for unknown reasons (data not shown). These two proteins, although purified by affinity column and further purified with HPLC gel filtration column, still contained some minor impurities (Fig.1, lanes 5, 6, 11 and 12).

The NIRs behaved quite differently in the SDSPAGE systems using tris-glycine as opposed to those employing tris-tricine as running buffer. In the trisglycine buffer system, NIR appears as monomeric and dimeric forms under non-denaturing condition and without heating before loading on the gel. But the enzyme migrated as the trimeric molecule in the tristricine buffer system under the same conditions (Fig.2). In fact, this trimer is rather stable in the tricine buffer system. After heating at $80^{\circ} \mathrm{C}$ in the

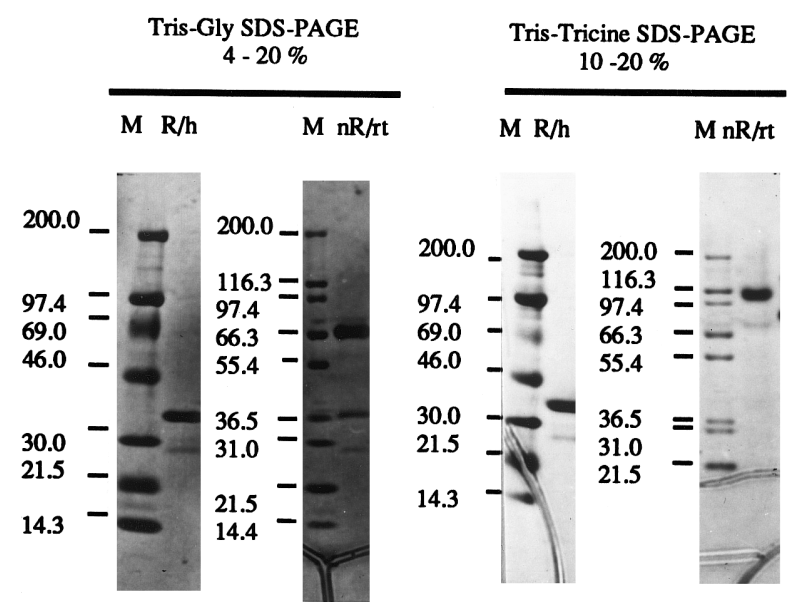

FIG. 2. The behavior of NIR in the tris-glycine and tris-tricine SDS-PAGE (left panel), and its calibrated molecular weight (right panel) in the tris-tricine system. R/h: samples treated with reducing agent and heated for $5 \mathrm{~min}$ at $95^{\circ} \mathrm{C} ; \mathrm{nR} / \mathrm{rt}$ : non-reduced samples kept at room temprature for $5 \mathrm{~min}$. $\mathrm{M}$ : the protein molecular weight makers (kDa): aprotinin: 6; Iysozyme: 14.4; trypsin inhibitor: 21.5; carbonic anhydrase: 31; lactate dehydrogenase: 36.5 ; glutamate dehydrogenase: 55.4 ; bovine serum albumin: 66.3 ; phosphorylase b: 97.4; $\beta$-galactosidase: 116.3; myosin: 200.

tricine system more than $5 \%$ of the NIR remained in the trimeric form (data not shown). It is clear that the tricine buffer, but not the glycine, could preserve the form of NIR observed in crystals. Apparently the noncovalent bonds holding the subunits together in the native states were not broken by SDS in this tricine buffer system at room temperature. Tris-tricine is thus a useful and convenient tool for checking the quaternary structures of NIR and its analogs.

By using this tricine SDS-PAGE without heating of samples before loading, we found that all of NIR analogs with an N-terminal extension-peptide, MRGSHHHHHHGSSRDDDDK, which was derived from the oligonucle otide spanning the ribosome-binding sequence and the codon for the N-terminus of mature NIR, migrated as the dimer and the monomer and could not assemble into active trimers (Fig.3 lanes 6,12,18,24,and 30). After digestion with enterokinase to remove that $\mathrm{N}$-terminal ex-

TABLE 1

The Subunit Molecular Weight and Enzyme Activity of NIR Analogs

\begin{tabular}{lcc}
\hline Analogs & Mol. wt. (kDa) & Rel. activity (\%) \\
\hline NIR & 37.1 & 100 \\
NIR+8 & 38.0 & 0 \\
RNIR* & 37.1 & 108 \\
NIR-5 & 36.6 & 72 \\
NIR-11 & 36.0 & 0 \\
NIR-17 & 35.2 & 0 \\
\hline
\end{tabular}

* Recombinant wild-type NIR. 


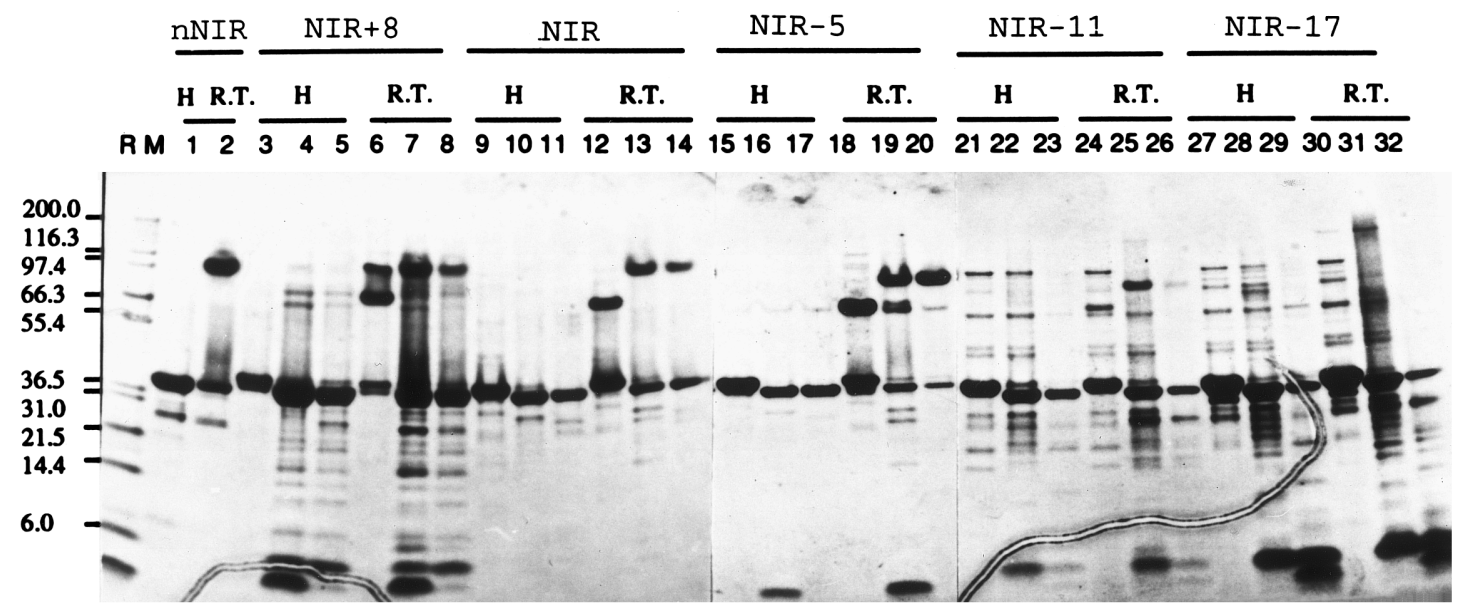

FIG. 3. The protein profile of the NIR analogs in the tris-tricine SDS-PAGE. RM: protein molecular weight maker; H: samples treated with reducing agent and heating; R.T.: samples treated with reducing agent and kept at room temperature for 5 min. Lanes $3,6,9$, 12, 15, 18, 21, 24, 27, and 30: samples before enterokinase digestion. Lanes 4, 7, 10, 13, 16, 19, 22, 25, 28, and 31: samples treated with enterokinase. Lanes 5,8,11,14,17,20,23,26,29, and 32: samples treated with enterokinase and dialyzed against $\mathrm{Cu}^{+2}$-containing buffer.

tra peptide, NIR+8 (Fig. 3, lanes 7 and 8), wild-type NIR (Fig.3, lanes 13,14) and NIR-5 (Fig.3, lanes 19 and 20) could assemble into trimer form. However, those NIR with deletion of longer peptides at C-terminus, i.e., NIR-11 and NIR-17 (Fig.3, lanes 25,26,31 and 32) could not form trimers. Thid experiments demonstrated the
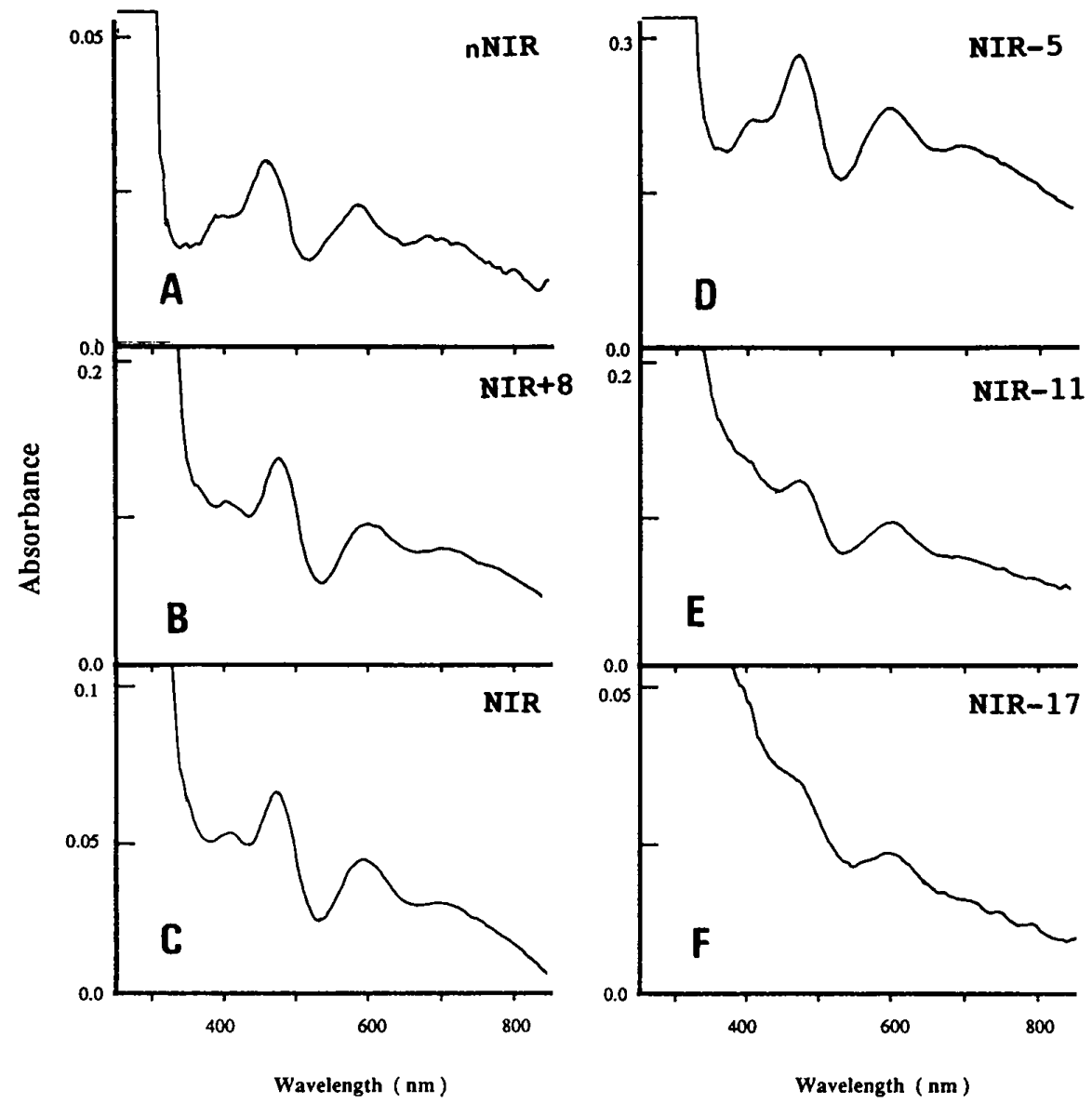

FIG. 4. The optical spectra of native, recombinant, and mutated NIRs. 
importance of the C-terminal segment for maintaining the trimeric structure. As expected, the enzyme assay showed that NIR-5 retained $72 \%$ of the native enzyme activity. Both NIR-11 and NIR-17 mutants were not enzymatically active (Table 1). Fig. 4 shows the optical spectra of native, recombinant and mututed NIR. Although the ratio $A_{280} / A_{458}$ is not very much affected (not shown), it is dear that the overall shape shows much distortion in the mutated proteins with no detectable NIR activity (NIR-11 and NIR-17). However, although the NIR +8 mutated protein shows what appears a typical spectrum this protein exhibits no enzymatic activity either. The capacity to form a trimer is apparently not sufficient for maintaining an active enzyme.

The X-ray crystallographic study by Godden et al. (8) shows that three factors determine maintenance the NIR trimer structure seen in the cryatal: 1 . the interaction between His306 and the type II copper; 2 . the inter-face between two nearby subunits; and 3. the C-terminal polypeptide from position 324 to 340 extend from one subunit to another. They proposed that the third is the major factor. In this report, we show that not only the extension of the $\mathrm{C}$-terminus will decrease the enzyme activity, but also the del etion will have the same effect. Deletion of more than ten residues in the C-terminus abol ishes NIR activity completely, whereas deletion of five permits retention of two thirds of the activity. This result is consistent with the conclusion that the C-terminal segment interacts with another subunit to maintain both the quaternary structure and the activity of the enzyme.

\section{ACKNOWLEDGMENT}

This study was supported by a grant from National Science Council of the Republic of China (NSC-85-2311-B-001-007-B15).

\section{REFERENCES}

1. Payne, W. J . (1985) Denitrification in the Nitrogen Cycle (Golteman, H. Ly, Ed.), Plenum, New York.

2. Zumft, W. G., Gotzmann, D. J ., and Kroneck, P. M. H. (1987) Eur. J . Biochem. 168, 301.

3. Kakutami, T., Watanabe, H., Arima, K., and Beppu, T. (1981) J. Biochem. 89, 463- 472.

4. Liu, M. Y., Liu, M. C., Payne, W. J ., and Le Gall, J . (1986) J . Bacteriol. 166, 604-608.

5. Kukimoto, M., Nishiyama, M., Murphy, M. E. P., Turley, S., Adman, E. T., Horinouchi, S., and Beppu, T. (1994) Biochemistry 33, 5246-5252.

6. Masako, M., I wasaki, H., Saturai, T., Suzuki, S., and Nakahara, A. (1984) J . Biochem. 69, 859-868.

7. Nishiyama, M., Suzuki, J., Kukimoto, M., Ohouki, T., Horinouch, S., and Beppu, T. (1993) J . Gen. Microbiol. 139, 725-733.

8. Godden, J . W., Turky, T., Teller, D. C., Adman, E. T., Liu, M. Y., Payne, W. J ., and Le Gall, J . (1991) Science 253, 438- 442.

9. Adman, E. T., Godden, J . W., and Turley, S. (1995) J . Biol. Chem. 270, 27458-27474.

10. Chen, J -Y., Chang, W.-C., Chang, T., Chang, W.-C., Liu, M.-Y., Payne, W. J., and Le Gall, J. (1996) Biochem. Biophy. Res. Comm. 219, 423- 428. 